\title{
GOVERNMENT RESEARCH IN AUSTRALIA COMMONWEALTH SCIENTIFIC AND INDUSTRIAL RESEARCH ORGANIZATION
}

$\mathrm{T}$

HE third annual report of the Commonwealth of Australia Scientific and Industrial Research Organization*, which now numbers fifteen divisions and expended more than $£ 3$ millions during the year, covers the year ended June 30, 1951, and again stresses the extent to which slow progress with the building projects handicaps the development of research programmes.

In spite of staff problems, the Division of Soils continued work on some fifteen soil surveys and a compilation of a manual of Australian soils was nearing completion. Chemical work on the basaltic soils from Lismore, New South Wales, was completed, studies on the availability to plants of copper and manganese continued, and an investigation into the ion exchange and $p \mathrm{H}$ relations of eation-dominant soils commenced. Studies on the stability of naturally occurring aggregates have shown that natural aggregation can be measured by a drop-shatter method, which has been used to help define the structure and consistency of soils of the Riverina and Abermusden districts.

During the year, 518 samples of seed and plant material, chiefly pasture and forage plants, were introduced from thirty-three countries for trial in Australia, and in the latter part of the year the active collection of plant materials in other countries was developed with the view of testing in Australia. Further trials have confirmed the value of Lathyrus ochrus as a green manure for use in vineyards especially on lighter soils, and of Phaseolus as grain legumes, while studies of flowering and seed-setting of introduced sunflower varieties continued. A section of plant genetics has been re-established and its work extended to include genetical and cytogenetical investigations of pasture species for Australian conditions, cereal problems not being pursued elsewhere, and problems in the resistance to disease of major vegetable crops such as the tomato and potato. The Plant Diseases Section has given special attention to the chemotherapeutic control of virus diseases, and investigations on the use of antibiotics for controlling plant diseases continued. Some six hundred further tests of native species were made for the presence of alkaloids, saponins, cyanogenetic glycosides and other chemical principles, and two hundred and fifty bulk samples were collected for more detailed examination. At Clare, Queensland, the two previous seasons investigations on the water requirements of tobacco showed that yield and quality were maintained over a wide range of treatments, and the effect of nitrogen-levels and rates of planting on quality was being investigated. Detailed studies of the nutritional requirements of subterranean clover are being continued under field, greenhouse and laboratory conditions; and other pasture investigations have included ecological studies on native and exotic pastures, nutrition and soil deficiencies, the use of pastures and maintenance of fertility. Weed investigations again indicated that plantgrowth regulating substances alone offer no prospect of controlling established skeleton weed (Chondrilla juncea). At the Katherine Research Station, the lime* Parliament of the Commonwealth of Australia Third Annual Report of the Commonwealth Scientiflc and Industrial Research Organization for the Year ending 30th June 1951. Pp. 167.
berra : Commonwealth Government Printer, 1952.) stone red soils of the Tipperary land system were being examined for determining the possibilities of agricultural development under dry-land conditions, while at the Kimberley Research Station agronomic and pasture problems under irrigation were being studied in co-operation with the Western Australia Department of Agriculture.

Research into problems of animal health and production at the McMaster Animal Health Laboratory, Sydney, included further studies with phonothiazine against internal parasites. Studies at the Veterinary Parasitology Laboratory, Yeerongpilly, Queensland, on the identification of the species of amphistomes infesting cattle have been completed, and evidenco obtained that the 'Queensland itch' of horses is associated with hypersensitivity to the bites of sandflies (Ceratopogonidæ); protection by regular spraying with DDT was being investigated. Progress is reported in the development of the Poultry Research Centre at Werribee, Victoria, and studies of the vitamin A requirements of sheep, the effects of zinc and copper deficiency on the biochemical processes involved in phosphorylation within the tissues of plants, on carbohydrate metabolism, and on sheep feeding with particular reference to drought conditions continued, as well as on the influence of nutrition on the breeding performance of merino ewes.

Besides its work on the cattle tick, the Division of Entomology obtained very promising results in co-operative work on the control of the Argentine ant in Sydney and in Western Australia, which points to the possibility of complete eradication of the ant. The expected outbreak of the Australian plague locust did not materialize during $1950-51$, and earlier work on the relation between trees and locust abundance was extended. A long-term experiment on the control with DDT of the pasture cockchafer, Aphodius howitti Hope, was concluded; but use of DD'T against the red-legged earth mite in pastures also infected with the lucerne flea (Sminthurus viridis L.) is not recommended. Work on biological control has emphasized the importance of detailed attention to the flora associated with a weed, both to ascertain the extent to which other plants are likely to assist the insects and to determine the species likely to replace the weed. In the Wildlife Section, the work on the virus disease of rabbits, myxomatosis, was given priority, and the night-biting mosquito, Culex annulirostris, was shown to be the principal vector along the Murray main stream. Of poisons now in use, only sodium fluoroacetate showed promise for rabbit control.

Fishories research at the Dunwich Field Station, Stradbroke Island, South Queensland, covered the distribution and movements of mullet in the estuarine and river phases of their history, the development of the oyster industry of Queensland, the distribution of prawns and preliminary work on lagoon fishfarming. The laboratory at Thursday Island, T'orres Strait, was equipped and progress is reported in the study of plankton and the biology of pearl oysters. To extend the oceanographical work, preliminary plans were prepared for an oceanographical research vessel to be constructed in Great Britain. Studies on fouling by marine growths continued at various points, and this work has revealed the importation, on ships bottoms, of fouling organisms from other 
countries. A programme covering the biology and distribution of Macrocystis aims at giving a reliable estimate of the quantity of this seaweed in Australian waters, the seasonal and long-term fluctuations in yield of the seaweed and its products, and the method of regeneration of the plant.

Food research included a detailed study of the performance of refrigerated railcars with end bunkers and coolers, which led to the preparation of a statement of the principles governing the use of these vehicles for chilled beef transport. An account of the work on the evaluation of canning processes was published. Studies of the temperature relations of Clostridium botulinium and of the factors affecting the germination of heat-treated bacterial spores continued, while much work was done on the development of rapid laboratory and field methods for estimating the degree of fish spoilage. The longer storage life of dehydrated sugared fruit compared with ordinary dehydrated fruit has been confirmed, and varieties of fruit and vegetables were being tested for suitability for freezing.

The anatomical studies of timbers from Malaya, Borneo and New Guinea have proved of considerable value, and attention has also been paid to the factors causing the death of medullary ray and vertical parenchyma cells in sapwood-heartwood. Activity in the wood preservation field markedly increased; a survey of the causes of failure of preservative treatment of cross-arms was completed in Western Australia, Victoria and New South Wales, and a laboratory study of the toxicity and permanence of water-borne preservatives was commenced. Research on the properties and uses of building materials continued in the Division of Building Research; but the only new project was the preparation of a paper on the weathering and durability of building materials in the tropics for the International Building Research Congress held in London in September 1951.

Wool textile research was extended to cover the improvement of wool as a textile fibre and the reduction of costs of production of woollen, worsted and felted materials, but several years must elapse before the new laboratories are fully staffed with adequately trained research workers. Considerable interest has been displayed in the two processes recommended by the Organization for the recovery of wool from sheepskin pieces and broken skins. A suitable method has been developed for the alkaline hydrolysis of wool wax to wax alcohols and acids, and the study of the formation of fibres under natural conditions has been continued in the Division of Industrial Chemistry, where much attention has also been given to the study of wool wax and sugarcane wax. Steps were taken to provide a more comprehensive microanalytical service for scientific institutions and industry. Attention was also being given to analytical problems in connexion with the uranium ores of South Australia, the chemistry of alunite and its utilization in the production of potash fertilizers, the physiologically active alkaloidal principle of the Dwalganup strain of subterranean clover, and to liquid and vapour equilibrium concentrations of binary mixtures and their variation with temperature or pressure, in relation to plant design. A satisfactory method of concentrating topaz (used in ceramic ware) has been devised. The Section of Physical Metallurgy was concerned mainly with the metallography of alloys of titanium, gas surface reactions of titanium, and the influence of prolonged stress on lead alloys.
The work of the Division of Tribophysics continued on the same lines as in the previous year, but was still hindered by lack of space; and that of the Division of Metrology was largely determined by its statutory responsibilities for Commonwealth standards. The Division of Physics was also concerned with research designed to improve the accuracy of the methods of maintenance of standards, to increase the accuracy of measurement, the determination of prcperties of materials at extremely low temperatures and the study of the physical processes associated with the emission of radiation from the sun, including the development of new techniques for the study of the ionosphere and improved navigational aids under Australian conditions. The work of the Section of Meteorological Physics was consolidated and extended on the previous lines, including the prevention of frosts in orchards, the physics of rain and clouds, and the artificial formation of rain. In the Section of Mathematical Statistics two further centres have been established to provide direct assistance to divisions of the Organization in their experimental work. The Organization continues to co-operate with the Physics Department of the University of Melbourne in research on nuclear physics and cosmic rays under the direction of Prof. L. H. Martin.

\section{AMERICAN SCIENTIFIC EQUIPMENT FOR BRITISH LABORATORIES}

$T$

HE last report of the director of the Chemical Research Laboratory, 'Teddington, acknowledged the indebtedness of the Laboratory to the European Co-operation Administration of the United States for the supply of equipment unobtainable in Britain, including a Podbielniak Hyd-Robot self-recording low-temperature fractional-distillation unit, a Beckmann flame spectrophotometer and a multi-source unit for spectrographic work. A list of scientific equiprnent to the value of more than $£ 350,000$ made available in this way, chiefly to the Department of Scientific and Industrial Research, but also to some twenty-four other research institutions throughout the United Kingdom, has now been published*. The equipment, much of which is obtainable only in the United States, has been made available for a wide range of industries, and about three-quarters of it has already been received. It includes such diverse items as: an anderometer, enabling investigations to be made on precision bearings used in machine-tool spindles, etc., with the view of improving economy and quality of production; a compact surface analyser ; a 'Falex' lubricant tester; multi-channel directreading spectrographs permitting the use of methods much in advance of existing rapid analytical technique; and a high-temperature dilatometer for research into moulding sand.

The National Physical Laboratory has been supplied with a set of valves for the construction of instruments for calibration in the frequency-range $2,660-10,000 \mathrm{Mc}$./s., a Carey recording spectrophotometer, a thallium boron-iodide prism, $K$-band klystron oscillators and crystal detectors, and with 'Fosterite' photoelastic material, as well as with nine Berkeley decimal electronic counting units. The Building Research Station has received two American explosive-actuated fastening tools as well as a portable

* Issued by the Industrial Correspondent, Mutual Security Agency, American Embassy, Grosvenor Square, London, W.1. 